\title{
Comparison of Adsorptive Removal of Total Nitrogen (T-N) and Total Phosphorous (T-P) in Aqueous Solution using Granular Activated Charcoal (GAC)
}

\author{
Keon Sang Ryoo*, Jong-Ha Choi, Yong Pyo Hong
}

Department of Applied Chemistry, Andong National University, Andong 760-749, Korea.

*Corresponding author : E-mail address: ksr@andong.ac.kr

\begin{abstract}
The present study is to explore the possibility of utilizing granular activated charcoal (GAC) for the removal of total phosphorous (T-P) and total nitrogen ( $\mathrm{T}-\mathrm{N})$ in aqueous solution. Batch adsorption studies were carried out to determine the influences of various factors like initial concentration, contact time and temperature. The adsorption data showed that GAC has a similar adsorption capacity for both T-N and T-P. The adsorption degree of T-N and T-P on GAC was highly concentration dependent. It was found that the adsorption capacity of GAC is quite favorable at a low concentration. At concentrations of $1.0 \mathrm{mg} \mathrm{L}^{-1}$ of T-P and $2.0 \mathrm{mg} \mathrm{L}^{-1}$ of T-N, approximately $97 \%$ of adsorption was achieved by GAC. The equilibrium data were fitted well to the Langmuir isotherm model. The pseudo-second-order kinetic model appeared to be the better-fitting model because it has higher $R^{2}$ compared with the pseudo-first-order and intra-particle kinetic model. The theoretical adsorption equilibrium $q_{e, c a l}$ from pseudo-second-order kinetic model were relatively similar to the experimental adsorption equilibrium $q_{\mathrm{e}, \text { exp }}$. To evaluate the effect of thermodynamic parameters at different temperatures, the change in free energy $\Delta G$, the enthalpy $\Delta H$ and the entropy $\Delta S$ were estimated. Except for adsorption of T-P at $278 \mathrm{~K}$, the $\Delta G$ values obtained were all negative at the investigated temperatures. It indicates that the present adsorption system occurs spontaneously. The adsorption process of T-N by GAC was exothermic in nature, whereas T-P showed endothermic behavior. In addition, the positive values of $\Delta S$ imply that there was the increase in the randomness of adsorption of T-N and T-P at GAC-solution interface.
\end{abstract}

\section{Keywords}

T-P; T-N; Granular activated charcoal; Adsorption; Isotherm

\section{Council for Innovative Research}

Peer Review Research Publishing System

Journal: Journal of Advances in Chemistry

Vol. 9, No. 1

editorjaconline@gmail.com

www.cirworld.org/journals 


\section{INTRODUCTION}

Nitrogen and phosphorous are essential nutrients necessary for all living cells as components of cell membrane. The industrial and agricultural activities of human have continually brought them into water bodies including reservoirs, lakes, streams and rivers. Consequently, they have exceeded the acceptable limits in many countries of the world. Their enrichment in water leads to the algal blooms. These high growths of algae in aquatic system adversely affect the water quality and impair water treatment processes. The Korean Ministry of the Environment has set a strict control of less than $0.6 \mathrm{mg} \mathrm{L}^{-1}$ of nitrogen and $0.025 \mathrm{mg} \mathrm{L}^{-1}$ of phosphorous in the water to escape from eutrophication problems.

There have been a lot of studies on the removal of nitrogen and/or phosphorous from wastewater using biological and chemical methods [1-6]. Biological methods such as biological nutrient removal (BNR) and membrane bioreactor process (MBR) have been used to eliminate nitrogen and phosphorous in wastewater. However, they have shown unstable and insufficient efficiencies in removing nitrogen and phosphorous from wastewater. Moreover, they have considerable difficulty in controlling microorganism due to the long-term biodegradation. Chemical methods have also been widely used as a viable alternative to biological methods. Nevertheless, their applicability of wastewater treatment has been limited in terms of the high cost of chemical additives and the production of chemical sludge.

Unlike the biological and chemical methods, adsorption is a quite popular method due to the simplicity and the absence of sludge, as well as the availability of a wide range of adsorbents. The important key to success of adsorption depends mainly on the choice of an adequate adsorbent. In general, adsorbent must satisfy the following preconditions [7,8]: $(1)$ a high capacity, selectivity and rate of adsorption; (2) a low cost; (3) no hazardous pollutants; (4) an easy recycle; (5) a high physical strength. Many investigators have attempted the removal of nitrogen and/or phosphorous from wastewater using various adsorbents such as activated alumina [9], ion exchange resin [10], synthetic zeolite [8], goethite [11], fly ash [12], red mud [13] and loess [14]. Of all adsorbents, activated carbon has been widely used in wastewater treatment for a long time and proven to be one of the most effective and reliable adsorbents [15-18]. Even though the high cost of activated carbon makes its use limited, it may be still a favorite choice as an adsorbent for removal of nitrogen and phosphorous from wastewater because of its high surface area and pore volume, along with convenient regeneration of spent carbon.

The present study is to explore the possibility of utilizing GAC for the adsorptive removal of T-N and T-P from aqueous solution. The effect of factors such as contact time, initial concentration and temperature was systematically investigated. Experimental equilibrium data were fitted to the Freundlich and Langmuir isotherm models to determine the best-fit isotherm equation. The kinetics of T-N and T-P adsorption on GAC was analyzed by fitting pseudo-first-order, pseudosecond-order and intra-particle diffusion kinetic models. In addition, thermodynamic parameters such as the change in Gibbs free energy $\Delta G$, the enthalpy $\Delta H$ and the entropy $\Delta S$ were also estimated to study the feasibility of the adsorption process.

\section{MATERIALS AND METHODS}

\subsection{Materials}

The T-N and T-P standard solutions were purchased from Kanto Chemical Co., Inc, Tokyo, Japan. The stock solutions of T-N and T-P were prepared by dissolving their standard solutions into distilled water. Distilled water prepared by a Milli$Q$ water system from Millipore, USA was used in all adsorption experiments. GAC was provided by Yakuri Pure Chemicals Co., Ltd., Kyoto, Japan. The mesh size of GAC is between 8 and 32.

\subsection{Adsorption studies}

Adsorption studies were carried out by the batch system to obtain the rate and the equilibrium data. For these studies, a series of $250 \mathrm{~mL}$ flasks were employed. Each flask was filled with $100 \mathrm{~mL}$ of T-N and T-P solutions and kept in a thermostatic shaker. A known amount of GAC was added into flasks and agitated at $200 \mathrm{rpm}$ for the desired time periods. The adsorption capacities of GAC were evaluated by varying different factors such as initial concentrations, contact time and temperatures. The initial concentrations of T-N and T-P in solution were in the range of 2.0 to 20.0 and 1.0 to $10.0 \mathrm{mg}$ $\mathrm{L}^{-1}$, respectively. Contact time was ranged from 1 to $24 \mathrm{~h}$. The temperatures were operated at 278,298 and $323 \mathrm{~K}$. At given time intervals, a fraction of the aqueous solution was withdrawn from the flasks. Subsequently, the solution was filtered and centrifuged to separate adsorbent. After centrifugation, the residual concentrations of T-N and T-P in the solution were determined by a UV/Visible spectrophotometer (S-3150, Scinco, USA) at the corresponding $\lambda_{\max }=220$ and $880 \mathrm{~nm}$, respectively.

\subsection{Analysis}

Specific surface area and pore volume of GAC were determined by $\mathrm{N}_{2}$ adsorption and desorption at $77 \mathrm{~K}$ using a Specific Surface Area Analyzer (ASAP-2010, Micromeritics, USA). GAC was degassed at $473 \mathrm{~K}$ for $4 \mathrm{~h}$, prior to measurement. The BET surface area was obtained by applying the Brunauer-Emmett-Teller (BET) equation to the adsorption data. The pore volume data were calculated by using BJH method. The $\mathrm{pH}$ of GAC was measured as follows: $0.1 \mathrm{~g}$ of GAC was mixed with $10 \mathrm{~mL}$ of distilled water and shaken for $24 \mathrm{~h}$ at $30{ }^{\circ} \mathrm{C}$. After filtration, the $\mathrm{pH}$ of solution was determined by a pH meter (Radiometer PHM 250 Ion Analyser, USA). 


\section{RESULTS AND DISCUSSION}

\subsection{Characterization of GAC}

The properties of GAC were presented in Table 1. It is seen that the BET surface area of GAC was determined as $653.97 \mathrm{~m}^{2} \mathrm{~g}^{-1}$ and its pore volume was found to be $0.66 \mathrm{~cm}^{3} \mathrm{~g}^{-1}$. The $\mathrm{pH}$ of GAC exhibited weak acidic property.

\subsection{Effect of contact time and initial concentration}

The batch adsorption studies were carried out with different initial T-N and T-P concentrations in the range of 2.0-20.0 and $1.0-10.0 \mathrm{mg} \mathrm{L}^{-1}$, respectively while maintaining $0.25 \mathrm{~g}$ of GAC. Fig. 1 represents the adsorption amounts of GAC for initial T-N and T-P concentrations plotted as a function of contact time. As shown in Fig. 1, GAC exhibited different adsorption equilibrium for T-N and T-P. T-N reached equilibrium in about $24 \mathrm{~h}$, whereas T-P took $12 \mathrm{~h}$ arriving at equilibrium. After equilibrium, the remaining concentrations of T-N and T-P in solution remained constant. The adsorption degree of T-N and T-P on GAC was highly concentration dependent. The adsorption percentage was found to be lower with increasing initial T-N and T-P concentration. Based on the initial concentrations, roughly $14-97$ and $20-97 \%$ of adsorption for T-N and T-P at equilibrium was accomplished by GAC, respectively.

\subsection{Adsorption isotherm}

Two widely used isotherm models, Freundlich and Langmuir isotherms, were employed to investigate the adsorption characteristics. Adsorption isotherms characterize the distribution of adsorbates between adsorbent and solution when adsorption equilibrium is reached at a constant temperature and provide parameters for designing and optimizing the adsorption batch system.

The Freundlich isotherm, which is an empirical equation for multi-layer adsorption of adsorbate onto heterogeneous surfaces [19], is expressed as follows:

$$
q_{e}=k_{f}\left(c_{e}\right)^{1 / n}
$$

Where, $q_{\mathrm{e}}\left(\mathrm{mg} \mathrm{g}^{-1}\right)$ is the amount of adsorbate adsorbed by adsorbent at equilibrium and $\mathrm{ce}_{\mathrm{e}}\left(\mathrm{mg} \mathrm{L}^{-1}\right)$ is the equilibrium concentration of adsorbate in solution. The $k_{f}$ is the Freundlich constant related to adsorption capacity. The $1 / n$ is a measure of the adsorbent affinity for the adsorbate or surface heterogeneity, becoming more heterogeneous as its value gets closer to 0 . For linearization of the data, the Freundlich equation is written in logarithmic form:

$$
\log q_{e}=\log k_{f}+\frac{1}{n} \log c
$$

A linear plot of $\log q_{\mathrm{e}}$ versus $\log c_{\mathrm{e}}$ yields a slope $1 / n$ and an intercept of log $k_{\mathrm{f}}$.

The Langmuir isotherm model describes mono-layer adsorption on homogeneous surface with no interaction between adjacent adsorbed adsorbates [20]. The Langmuir isotherm is written as:

$$
\frac{c_{e}}{q_{e}}=\frac{1}{Q b}+\frac{c_{e}}{Q}
$$

Where, $Q\left(\mathrm{mg} \mathrm{g}^{-1}\right)$ and $b\left(\mathrm{~L} \mathrm{mg}^{-1}\right)$ are empirical constants representing the mono-layer adsorption capacity and the energy of adsorption, respectively, and the plot of $c_{e} / q_{e}$ against $c_{e}$ yields a straight line with the slope $1 / Q$ and the intercept $1 / Q b$.

The plots of Freundlich and Langmuir isotherm of T-N and T-P on GAC at $298 \mathrm{~K}$ are presented in Fig. 2 and 3 , and the corresponding isotherm parameters are listed in Table 2. It was observed that the experimental data for T-N and T-P adsorption deviates more in case of the Freundlich than Langmuir plot. This is further verified by the correlation coefficient $\left(R^{2}\right)$ value, shown in Table 2, of the linear plots. It is evident that the Langmuir isotherm fits the experimental data better than the Freundlich isotherm, suggesting the good applicability of the Langmuir model to this adsorption.

The Langmuir adsorption capacity of GAC for adsorption of T-N and T-P was found to be 11.61 and $8.36 \mathrm{mg} \mathrm{g}^{-1}$, respectively. In case of Langmuir isotherm model, the type of adsorption is classified by a dimensionless constant separation factor $r$ [21] which is given by the following equation:

$$
r=\frac{1}{1+b c_{i}}
$$

Where, $c_{1}\left(\mathrm{mg} \mathrm{L}^{-1}\right)$ is the initial adsorbate concentration. The $r$ values greater than 1 indicate unfavorable type of adsorption while the values between 0 and 1 represent favorable adsorption. In this study, the $r$ values lie within $0.014-$ 0.123 and $0.028-0.226$ for initial T-N and T-P concentrations, respectively. These values reflect that GAC favors the adsorption of T-N and T-P from solution in the studied concentration ranges.

Compared with the Langmuir isotherm model, the $R^{2}$ values of Freundlich isotherm model were slightly lower and found to be 0.9849 and 0.9701 for T-N and T-P, respectively. It can be said that the experimental data for adsorption of T-N and T-P can be also adequately described by the Freundlich isotherm model. The value of $1 / n$, one of the Freundlich isotherm constants, explains the type of isotherm. The adsorption is favorable when $1 / n$ is between 0 and 1 . Whereas, when $1 / n$ is larger than 1, the adsorption is unfavorable [22]. The values of $1 / n$ obtained from experimental data for T-N and T-P in this study were 0.07 and 0.13 , respectively, indicating that T-N and T-P are adsorbed favorably by GAC. 


\subsection{Adsorption kinetics}

To interpret the adsorption kinetics and the rate-determining step of T-N and T-P by GAC, the pseudo-first-order [23], pseudo-second-order [24] and intra-particle diffusion [25] kinetic models were employed. These kinetic models are based on the assumption that the rate of adsorption is proportional to the number of free sites, the square of the number of unoccupied sites and the boundary layer thickness, respectively. The conformity between experimental data and the model-predicted values was expressed by the correlation coefficient $R^{2}$. The relatively higher value is more applicable model to the kinetics of T-N and T-P adsorption.

The pseudo-first-order kinetic model is given as:

$$
\log \frac{q_{e}}{q_{e}-q_{t}}=\frac{k_{1}}{2.303} t
$$

Eq. (5) can be rearranged to obtain a linear form:

$$
\log \left(q_{e}-q_{t}\right)=\log q_{e}-\frac{k_{1}}{2.303}
$$

Where, $k_{1}\left(\mathrm{~min}^{-1}\right)$ is the equilibrium rate constant of the pseudo-first-order adsorption. The values of $q_{e}$ and $k_{1}$ are determined from the slope and intercept of the straight line.

The pseudo-second-order kinetic model is presented as:

$$
\begin{aligned}
& \frac{1}{q_{e}-q_{t}}=\frac{1}{q_{e}}+k_{2} \\
& \frac{t}{q_{t}}=\frac{1}{k_{2} q_{e}^{2}}+\frac{1}{q_{e}}
\end{aligned}
$$

Where, $k_{2}\left(\mathrm{~g} \mathrm{mg}^{-1} \mathrm{~min}^{-1}\right)$ is the equilibrium rate constant of the pseudo-second-order adsorption. The values of $q_{\mathrm{e}}$ and $k_{2}$ are obtained from the slope and intercept of the straight line.

The intra-particle diffusion model is written as:

$$
\log q_{t}=k_{i d} t^{1 / 2}+C
$$

Where, $k_{\text {id }}\left(\mathrm{mg} \mathrm{g}^{-1} \mathrm{~min}^{-1 / 2}\right)$ is the intra-particle diffusion rate constant and $C\left(\mathrm{mg} \mathrm{g}^{-1}\right)$ is the intercept which reflects the boundary layer effect. The values of $k_{i d}$ are determined from the slope and intercept of the straight line.

Figs. 4-6 represent the plots of the pseudo-first-order, pseudo-second-order and intra-particle diffusion kinetic models fitting to the experimental data for GAC at different initial T-N and T-P concentrations. The experimental amounts of adsorption equilibrium $q_{e, e x p}$, the rate constants of corresponding kinetic models $k_{1}, k_{2}$ and $k_{i d}$, the calculated amount of adsorption equilibrium $q_{\mathrm{e}, \text { cal }}$ and the correlation coefficients $R^{2}$ are listed in Table 3 and 4 .

From Table 3 and 4, it was observed that the calculated amounts of adsorption equilibrium $q_{\mathrm{e}, \mathrm{cal}}$ from pseudo-secondorder kinetic model are relatively similar to the experimental amounts of adsorption equilibrium $q_{e_{2} \text { exp. }}$ Moreover, the pseudo-second-order kinetic model appeared to be the better-fitting model because it has higher $R^{2}$ than those of the pseudo-second-order and intra-particle diffusion kinetic models for GAC. The correlation coefficients $R^{2}$ for the pseudosecond-order kinetic model are very close to 1.0 for all initial T-N and T-P concentrations. These results suggest that the $\mathrm{T}-\mathrm{N}$ and T-P adsorption on GAC follows the pseudo-second-order kinetic model. Furthermore, the value of pseudosecond-order kinetic rate constant $k_{2}$ depends on the experimental conditions like initial concentration, the $\mathrm{pH}$ of solution and temperature. As a rule, $k_{2}$ decreases with increasing initial adsorbate concentrations [26]. In this study, the rate constants $k_{2}$ decreased when the initial concentration increased. It is shown that the T-N and T-P solution with the lowest concentration is easily equilibrated by GAC.

The adsorption process of adsorbates from aqueous solution onto adsorbent generally occurs through three consecutive steps [27]: (1) transport of adsorbates from boundary layer to the surface of adsorbent (film diffusion); (2) transport of adsorbates within the pores of adsorbent (pore or intra-particle diffusion); (3) adsorption of adsorbates on the interior surface of adsorbent. Among three steps, the third step is very fast and does not represent the rate-determining step in the adsorption process. So, the adsorption rate is normally determined by the film and/or intra-particle diffusion steps [28]. If the plot gives a straight line and pass through the origin, the adsorption process is controlled only by the intra-particle diffusion. On the other hand, if the plot shows multi-linearity or does not pass through the origin, the adsorption process is controlled by two or more diffusion mechanism [22]. As seen from Fig. 6, the plots of $q_{\mathrm{t}}$ versus $t_{1 / 2}$ were linear for all initial concentrations and straight lines did not pass through the origin. These results suggest that the adsorption process of T-N and T-P on GAC may be controlled by both film and intra-particle diffusion, rather than only film or intra-particle diffusion. 


\subsection{Adsorption thermodynamics}

To study the effect of temperature on adsorption, adsorption kinetic experiments were further carried out using different temperatures $(278,298$ and $323 \mathrm{~K})$ with contact time at the selected T-N $\left(5.0 \mathrm{mg} \mathrm{L}^{-1}\right)$ and T-P $\left(2.5 \mathrm{mg} \mathrm{L}^{-1}\right)$ concentrations. As the pseudo-second-order kinetic model is better in describing T-N and T-P adsorption at above temperatures, the activation energy of adsorption $E_{\mathrm{a}}$ was obtained from the pseudo-second-order constant $k_{2}$ by using the following Arrhenius equation:

$$
\ln k_{2}=\ln A-\frac{E_{a}}{R T}
$$

Where, $A$ is the pre-exponential factor or the frequency factor and $R$ is the gas constant $\left(8.314 \mathrm{~J} \mathrm{~mol}^{-1} \mathrm{~K}^{-1}\right) . T(\mathrm{~K})$ is the absolute temperature.

The corresponding plots of the values of $\ln k_{2}$ against $1 / T$ at different temperatures were drawn and then the data were calculated to obtain the activation energy. The physical adsorption processes usually have low activation energies $(5-40 \mathrm{k}$ $\mathrm{J} \mathrm{mol}^{-1}$ ), while higher activation energies $\left(40-800 \mathrm{k} \mathrm{J} \mathrm{mol}^{-1}\right)$ are characteristic for chemical adsorption. As given in Table 5, the values of $E_{\mathrm{a}}$ for T-N and T-P were found to be $2.8-5.2 \mathrm{k} \mathrm{J} \mathrm{mol}^{-1}$. It can be suggested that the adsorption of T-N and T-P on $\mathrm{GAC}$ is physical in nature, considering that the values of $E_{\mathrm{a}}$ are in the typical range for physical adsorption.

In order to study the feasibility of the process and application of the present adsorbent, the thermodynamic parameters such as the change in free energy $(\Delta G)$, the enthalpy $(\Delta H)$ and the entropy $(\Delta S)$ were determined by using the following equations:

$$
\begin{gathered}
K_{d}=\frac{c_{e}}{q_{e}} \\
\Delta \mathrm{G}=-\mathrm{RT} \ln K_{d} \\
\Delta \mathrm{G}=\Delta \mathrm{H}-\mathrm{T} \Delta \mathrm{S}
\end{gathered}
$$

Where, $K_{d}$ is the distribution coefficient $\left(\mathrm{L} \mathrm{g}^{-1}\right)$ for the adsorption.

The enthalpy $\Delta H$ and entropy $\Delta S$ were evaluated by using the following equation:

$$
\operatorname{Rln} k_{d}=\Delta \mathrm{S}-\Delta \mathrm{H} \frac{1}{T}
$$

The $\Delta H$ and the $\Delta S$ values were obtained from the slope and the intercept of the straight line.

Plots of In $k_{d}$ versus $1 / \mathrm{T}$ are presented in Fig. 7. The values of the above parameters were calculated and are given in Table 5. Generally, the negative values of $\Delta G$ indicate the spontaneous nature of the adsorption process. As seen from Table 5, the values of $\Delta G$ were negative at the studied temperatures except for T-P at $278 \mathrm{~K}$. It reflects that the adsorption process of T-P is involuntary at low temperature. Nevertheless, we can conclude that adsorption process of the present adsorbate-adsorbent system is fairly spontaneous in nature. Meanwhile, the $\Delta G$ values decreased from -1.76 to -3.22 for $\mathrm{T}-\mathrm{N}$ and from 0.43 to $-0.96 \mathrm{k} \mathrm{J} \mathrm{mol}^{-1}$ for T-P with the increasing temperatures, indicating that the adsorption became more favorable at higher temperatures (Akar et al., 2013). It is noted that the $\Delta G$ value, up to $-20 \mathrm{k} \mathrm{J}$ mol $^{-1}$ is indicative of physical adsorption, while more negative than $-40 \mathrm{k} \mathrm{J} \mathrm{mol}^{-1}$ indicates chemical adsorption. In addition, when $\Delta G$ value is in the range of -20 and $-40 \mathrm{k} \mathrm{J} \mathrm{mol}^{-1}$, both physical and chemical adsorptions are responsible for adsorption (Khani, 2011). Therefore, it is clear that adsorption process of T-N and T-P by GAC can be explained by taking physical adsorption into consideration. In this study, the $\Delta H$ value of T-N was negative at the studied temperature ranges, but T-P exhibited positive values. Typically, the positive values of $\Delta H$ confirm the endothermic nature of the overall adsorption process, whereas the negative values suggest the exothermic nature. The positive values of $\Delta S$ obtained suggest that adsorption of $\mathrm{T}-\mathrm{N}$ and T-P on GAC is aided by increased randomness at the adsorbent-solution interface.

\section{CONCLUSIONS}

The capability of GAC for adsorption of T-N and T-P from aqueous solution was evaluated. The observed adsorption data showed that GAC has a similar adsorption capacity for T-N and T-P. The adsorption degree of T-N and T-P by GAC was dependant on the initial concentration. At initial concentration ranges investigated, approximately 14-97 and 20-97\% of adsorption for T-N and T-P at equilibrium was achieved by GAC, respectively. The adsorption isotherm study showed that the adsorption of T-N and T-P on GAC follows the Langmuir isotherm model due to the higher $R^{2}$ value than the Freundlich isotherm model. The adsorption kinetics was more appropriately described by the pseudo-second-order model rather than pseudo-first-order and intra-particle diffusion model. The values of $\Delta G$ were calculated at different temperatures and found to be negative except for T-P at $278 \mathrm{~K}$. The negative values of $\Delta G$ reflect that the adsorption is a favorable and spontaneous process. The adsorption of T-N by GAC was an exothermic process. On the contrary, the adsorption of T-P exhibited endothermic nature. Moreover, the positive $\Delta S$ value obtained also illustrates the increased randomness at the adsorbent-solution interface during the adsorption of T-N and T-P on GAC. 


\section{ACKNOWLEDGMENTS}

This work was supported by the National Research Foundation of Korea (NRF) Grant funded by the Korean Government (MOE) (No. 2013R1A1A2013257).

\section{REFERENCES}

(1) Guan, B., Yao, X., Jiang, J., Tian, Z., An, S., Gu, B., Cai, Y., 2009. Ecological Eng. 35, 576-581.

(2) Yang, J., Wang Su., Lu, Z., Lou, S., 2009. J. Hazard. Mater. 168, 331-337.

(3) Choi, J., Lee, S., Park, K., Lee, K., Kim, K., Kim, D., Lee, S., 2011. Desalination 266, 281-285.

(4) Johir, M.A.H., George, J., Vigneswaran, S., Kandasamy, J., Grasmick, A., 2011. Desalination 275. 197-202.

(5) Ding, A., Qu, F., Liang, H., Ma, Jun., Han, Z., Yu, H., Guo, S., Li, G., 2013. Chem. Eng. J. 223, 908-914.

(6) Littler, J., Geroni, J.N., Sapsford, D.J., Coulton, R., Griffiths, A.J., 2013. Chemosphere 90, 1533-1538.

(7) Urano, K., Tachikawa, H., 1991. Ind. Eng. Chem. Res. 30, 1893-1896.

(8) Onyango, M.S., Kuchar, D., Kubota, M., Matsuda, H., 2007. Ind. Eng. Che. Res. 46, 894-90.

(9) Brattebo, H., Odegaard, H., 1986. Water Res. 20, 977-986.

(10) Chen, J.P., Chau, M.L., Zhang, B., 2002. Waste Manage. 22, 711-719.

(11) Ler, A., Stanforth, R., 2003. Environ. Sci. Technol. 37, 2694-2700.

(12) Ugurlu, A., Salman, B., 1998. Environ. Int. 24, 911-918.

(13) Huang, W., Wang, S., Zhu, Z., Li, L., Yao, V., Rudolph, V., Haghseresht, F., 2008. J. Hazard. Meter. 158, 34-42.

(14) Park, J.H., Jung, D.I., 2011. Desalination 269, 104-110.

(15) Pikaar, I., Koelmans, A.A., van Noort, P.C.M., 2006. Chemosphere 65. 2343-2351.

(16) Gomez, V., Larrechi, M.S., Callao, M.P., 2007. Chemosphere 69, 1151-1158.

(17) Richard D., de Lourdes Delgado Nunez, M., Schweich, D., 2009. Chem. Eng. J. 148, 1-7.

(18) Richard D., de Lourdes Delgado Nunez, M., Schweich, D., 2010. Chem. Eng. J. 158, 213-219.

(19) Mohanthy, K., Naidu, J.T., Meikap, B.C., Biawas, M.N., 2006. Ind. Eng. Chem. Res. 45, 5165-5171.

(20) Nadaroglu, H., Kalkan, E., Demir, N., 2010. Desalination 251, 90-95.

(21) Palanisamy, P.N., Sivakumar, P., 2009. Desalination 249, 388-397.

(22) Vasiliu, S., Bunia, I., Racovita, S., Neagu, V., 2011. Carbohydr. Polym. 85 (2), 376-387.

(23) Lagergren, S., 1898.. Kungl. Svenska Vetenskapsakademien. Handlinger Band 24, 1-39.

(24) Ho, Y.S., Mckay, G., 1998. Can. J. Chem. Eng. 76 (4), 822-827.

(25) Weber, W.J., Morris, J.C., 1963. J. Sanitary Eng. Div., Am. Civil Eng. 89, 31-39.

(26) Salam, M.A., Al-Zhrani, G., Kosa, S.A., 2012. C. R. Chimie 15, 398-408.

(27) Yousef, R.I., El-Eswed, B., Al-Muhtaseb, A.H., 2011. Chem. Eng. J. 171, 1143-1149.

(28) Sun, C.M., Zhang, G.H., Qu, R.J., Yu, Y., 2011. Chem. Eng. J. 170, 250-257. 
Table 1

Properties of GAC

\begin{tabular}{lc}
\hline BET surface area $\left(\mathrm{m}^{2} \mathrm{~g}^{-1}\right)$ & 653.97 \\
Micropore surface area $\left(\mathrm{m}^{2} \mathrm{~g}^{-1}\right)$ & 294.71 \\
External surface area $\left(\mathrm{m}^{2} \mathrm{~g}^{-1}\right)$ & 359.26 \\
Pore volume $\left(\mathrm{m}^{3} \mathrm{~g}^{-1}\right)$ & 0.66 \\
Micropore volume $\left(\mathrm{m}^{3} \mathrm{~g}^{-1}\right)$ & 0.13 \\
Average pore diameter $(\mathrm{nm})$ & 4.03 \\
$\mathrm{pH}$ & 5.6 \\
\hline
\end{tabular}

Table 2

\begin{tabular}{cccccccc}
\hline & \multicolumn{3}{c}{ Freundlich constants } & \multicolumn{3}{c}{ Langmuir constants } \\
\hline & $\begin{array}{c}k_{f} \\
\left(\mathrm{mg} \mathrm{g}^{-1}\right)\end{array}$ & $1 / n$ & $R^{2}$ & $Q$ & $b$ & $R^{2}$ \\
$\left(\mathrm{mg} \mathrm{g}^{-1}\right)$ & $\left(\mathrm{L} \mathrm{mg}^{-1}\right)$ & 0.9994 \\
T-N & 18.09 & 0.07 & 0.9849 & 11.61 & 3.56 & 3.42 & 0.9996 \\
T-P & 4.67 & 0.13 & 0.9701 & 8.36 & 369 \\
\hline
\end{tabular}

Freundlich and Langmuir constants for adsorption of T-N and T-P on GAC at $298 \mathrm{~K}$

Table 3

Pseudo-first-order, pseudo-second-order and intra-particle diffusion kinetic model parameters for different initial T-N concentration

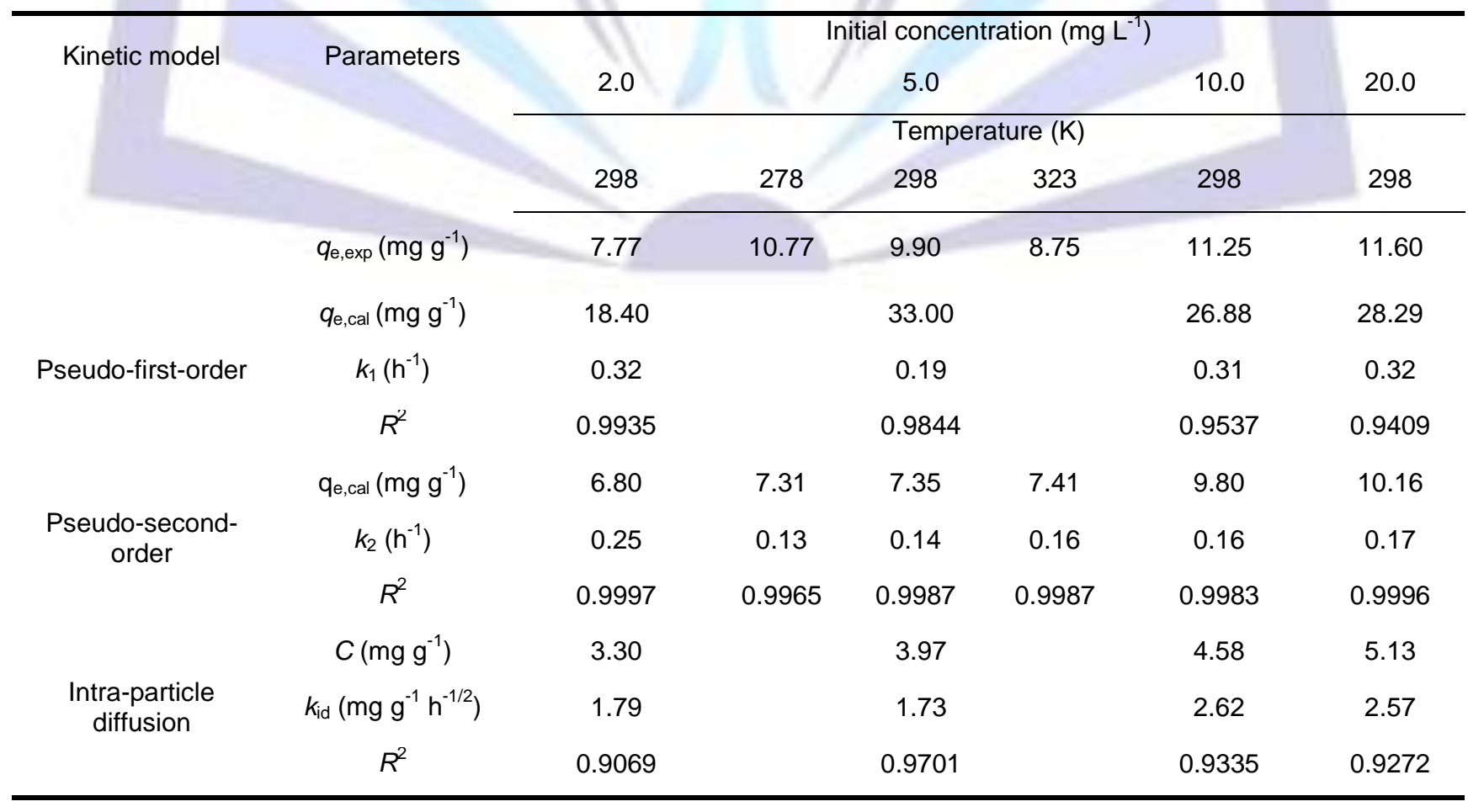


Table 4

Pseudo-first-order, pseudo-second-order and intra-particle diffusion kinetic model parameters for different initial T-P concentration

\begin{tabular}{|c|c|c|c|c|c|c|c|}
\hline \multirow{6}{*}{ Kinetic model } & \multirow{4}{*}{ Parameters } & \multicolumn{6}{|c|}{ Initial concentration $\left(\mathrm{mg} \mathrm{L}^{-1}\right)$} \\
\hline & & \multicolumn{2}{|l|}{1.0} & \multicolumn{2}{|l|}{2.5} & \multirow[t]{2}{*}{5.0} & \multirow[t]{2}{*}{10.0} \\
\hline & & \multicolumn{4}{|c|}{ Temperature $(\mathrm{K})$} & & \\
\hline & & 298 & 278 & 298 & 323 & 298 & 298 \\
\hline & $q_{\mathrm{e}, \exp }\left(\mathrm{mg} \mathrm{g}^{-1}\right)$ & 3.90 & 7.51 & 6.92 & 6.37 & 7.96 & 8.32 \\
\hline & $q_{\mathrm{e}, \mathrm{cal}}\left(\mathrm{mg} \mathrm{g}^{-1}\right)$ & 10.67 & & 17.68 & & 25.20 & 24.58 \\
\hline \multirow[t]{3}{*}{ Pseudo-first-order } & $k_{1}\left(\mathrm{~h}^{-1}\right)$ & 0.30 & & 0.24 & & 0.20 & 0.22 \\
\hline & $R^{2}$ & 0.9983 & & 0.9876 & & 0.9838 & 0.9916 \\
\hline & $\mathrm{q}_{\mathrm{e}, \mathrm{cal}}\left(\mathrm{mg} \mathrm{g}^{-1}\right)$ & 3.42 & 5.91 & 5.44 & 4.82 & 6.04 & 6.49 \\
\hline \multirow[t]{3}{*}{$\begin{array}{l}\text { Pseudo-second- } \\
\text { order }\end{array}$} & $k_{2}\left(\mathrm{~h}^{-1}\right)$ & 0.63 & 0.16 & 0.18 & 0.20 & 0.17 & 0.17 \\
\hline & $R^{2}$ & 0.9990 & 0.9985 & 0.9962 & 0.9975 & 0.9908 & 0.9941 \\
\hline & $C\left(\mathrm{mg} \mathrm{g}^{-1}\right)$ & 2.06 & & 2.20 & & 3.15 & 3.27 \\
\hline \multirow{2}{*}{$\begin{array}{l}\text { Intra-particle } \\
\text { diffusion }\end{array}$} & $k_{\text {id }}\left(\mathrm{mg} \mathrm{g}^{-1} \mathrm{~h}^{-1 / 2}\right)$ & 0.71 & & 1.62 & & 1.48 & 1.65 \\
\hline & $R^{2}$ & 0.9769 & & 0.9829 & & 0.9872 & 0.9905 \\
\hline
\end{tabular}

Table 5

Activation energy Ea values at different temperature ranges

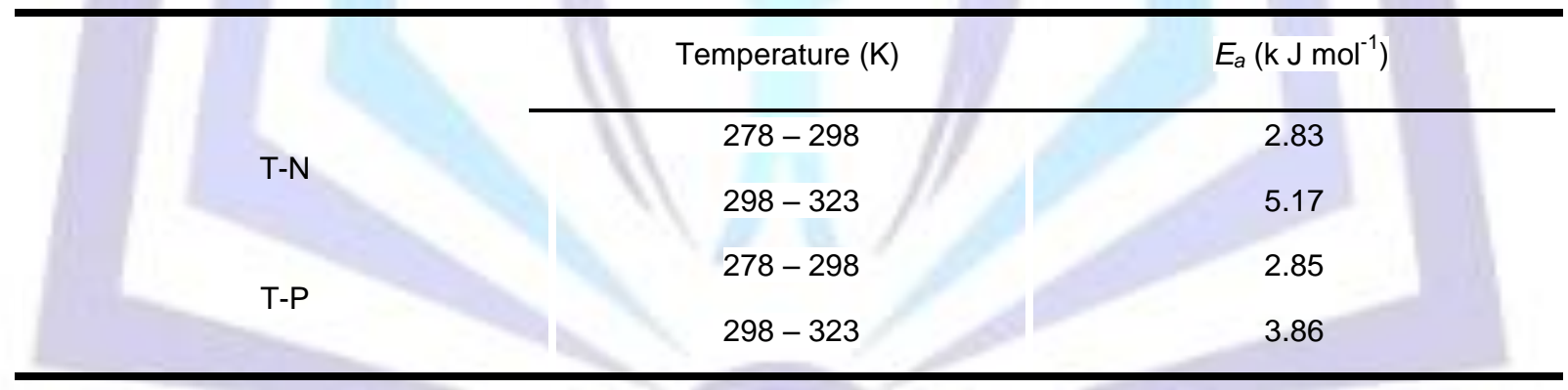


Table 6

Thermodynamic parameters for T-N and T-P adsorption on GAC

\begin{tabular}{|c|c|c|c|c|c|}
\hline & \multicolumn{3}{|c|}{$\Delta G\left(\mathrm{k} \mathrm{J} \mathrm{mol}^{-1}\right)$} & \multirow[t]{2}{*}{$\Delta H\left(\mathrm{k} \mathrm{J} \mathrm{mol}{ }^{-1}\right)$} & \multirow[t]{2}{*}{$\Delta S\left(\mathrm{~J} \mathrm{~mol}^{-1} \mathrm{~K}^{-1}\right)$} \\
\hline & $278 \mathrm{~K}$ & $298 \mathrm{~K}$ & $323 \mathrm{~K}$ & & \\
\hline $\mathrm{T}-\mathrm{N}$ & -1.76 & -2.32 & -3.22 & -7.25 & 26.40 \\
\hline T-P & 0.43 & -0.26 & -0.96 & 9.02 & 30.90 \\
\hline
\end{tabular}

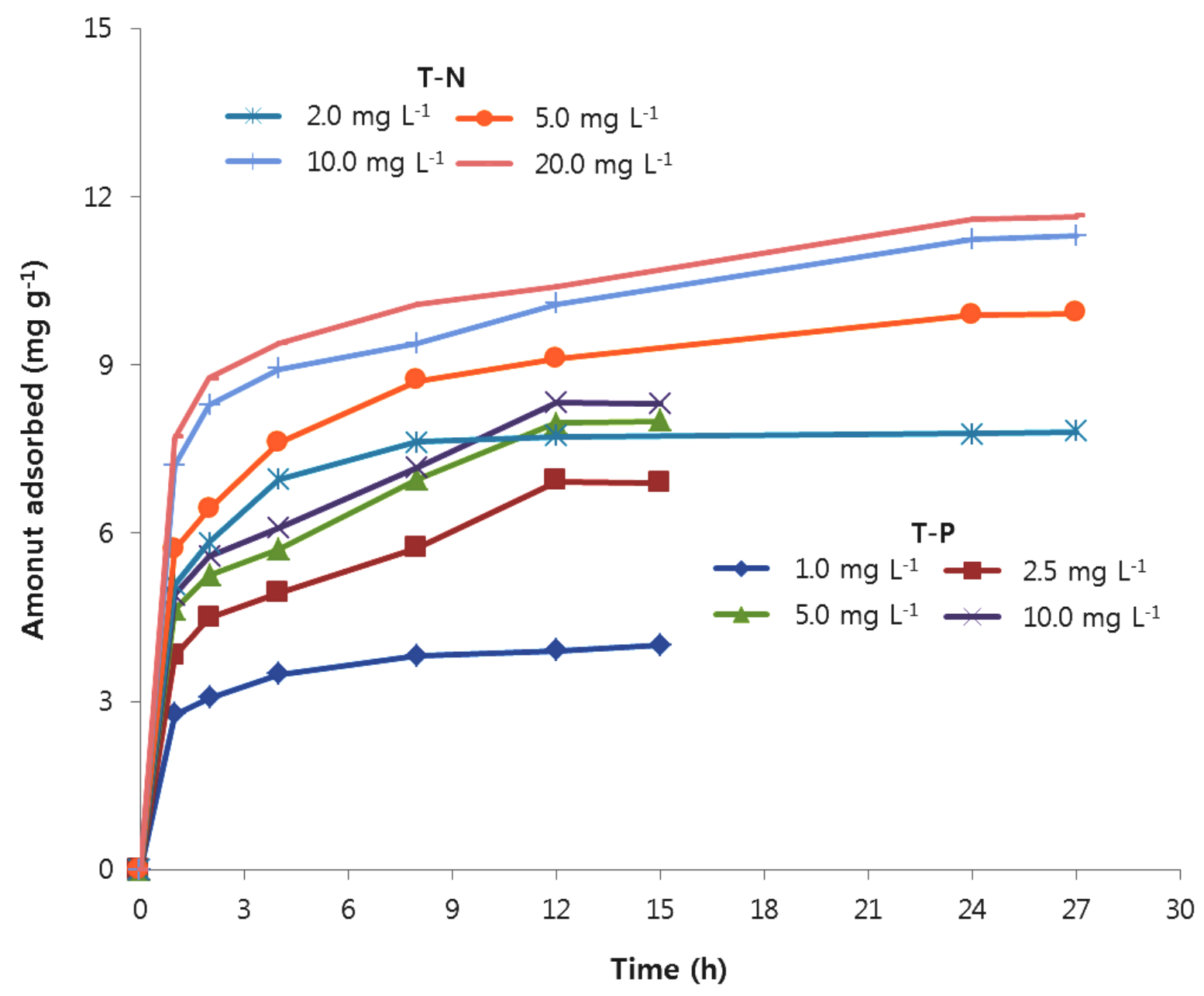

Fig. 1. Adsorption of T-N and T-P on GAC at $298 \mathrm{~K}$. 


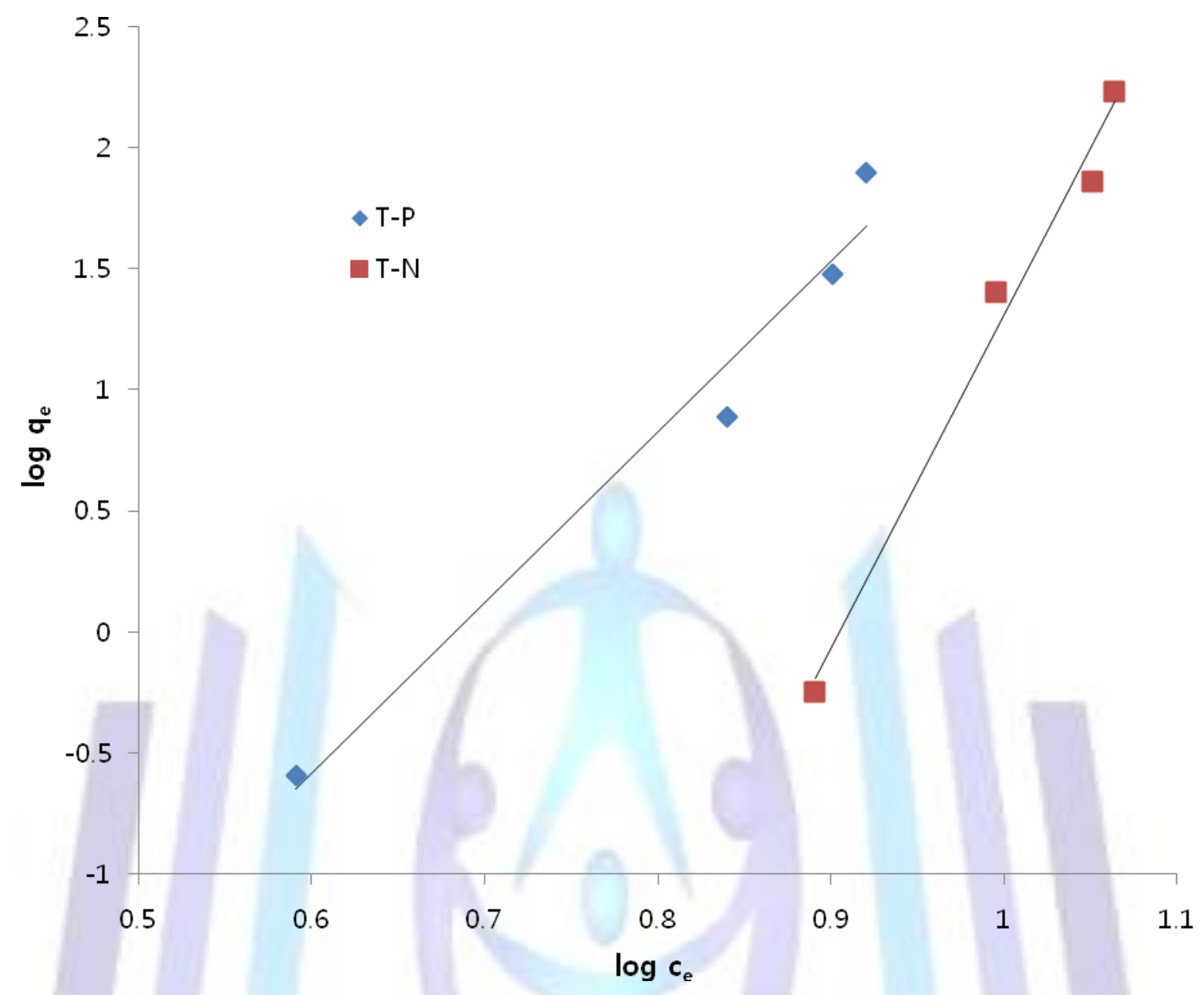

Fig. 2. Freundlich adsorption isotherm curve for T-N and T-P at $298 \mathrm{~K}$. 


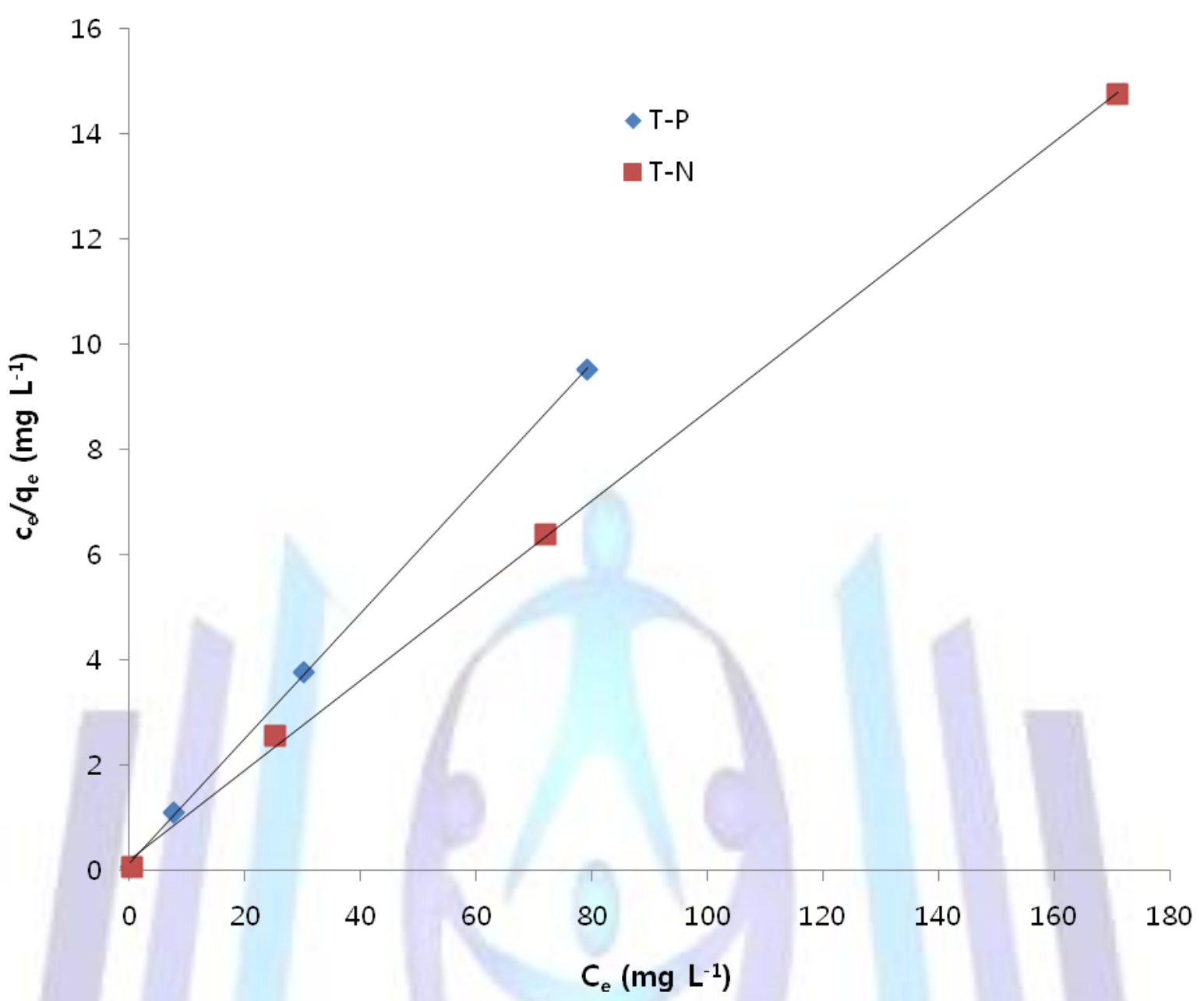

Fig. 3. Langmuir adsorption isotherm curve for T-N and T-P at $298 \mathrm{~K}$. 


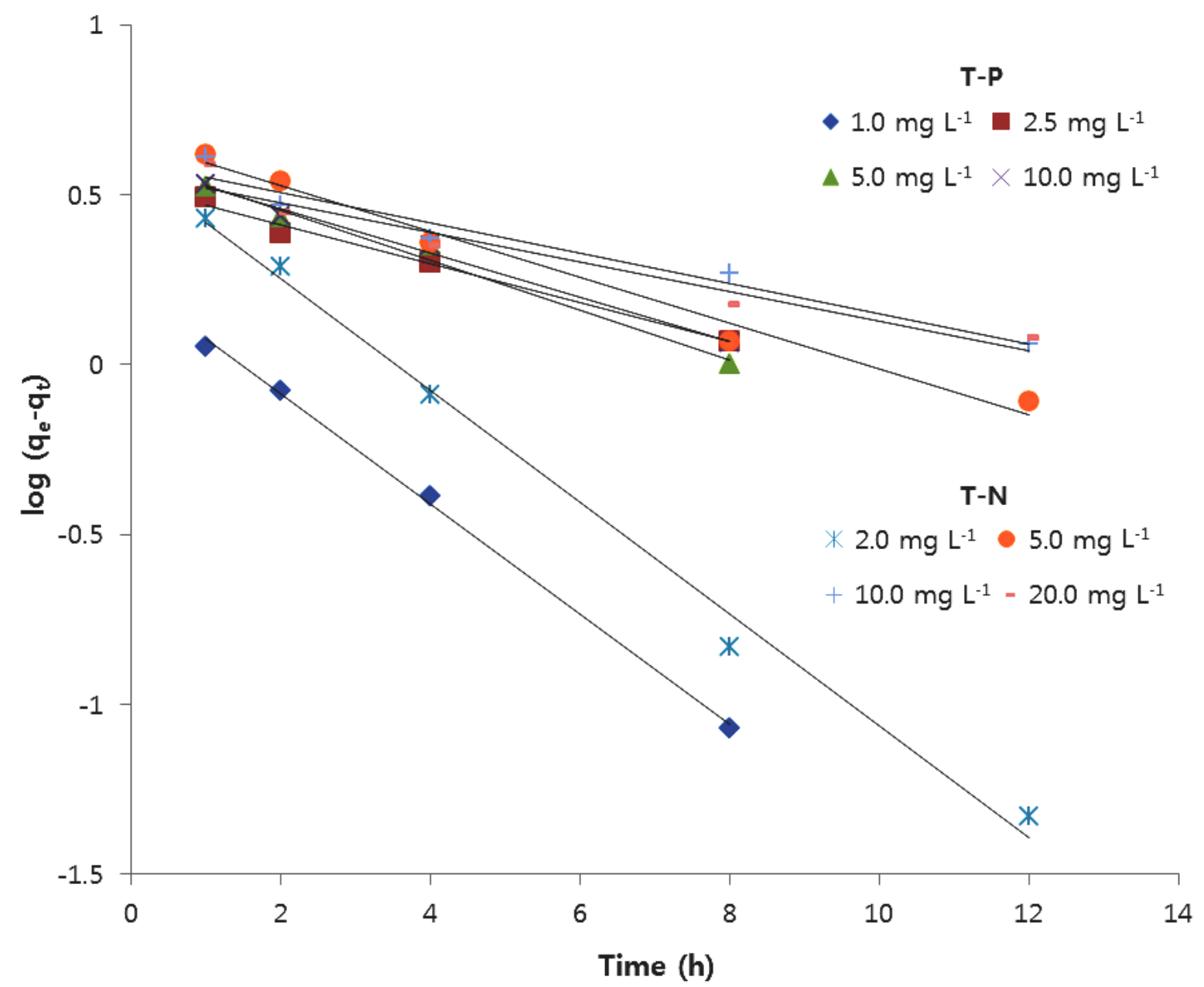

Fig. 4. Plots of pseudo-first-order kinetics of T-N and T-P adsorption on GAC at $298 \mathrm{~K}$. 


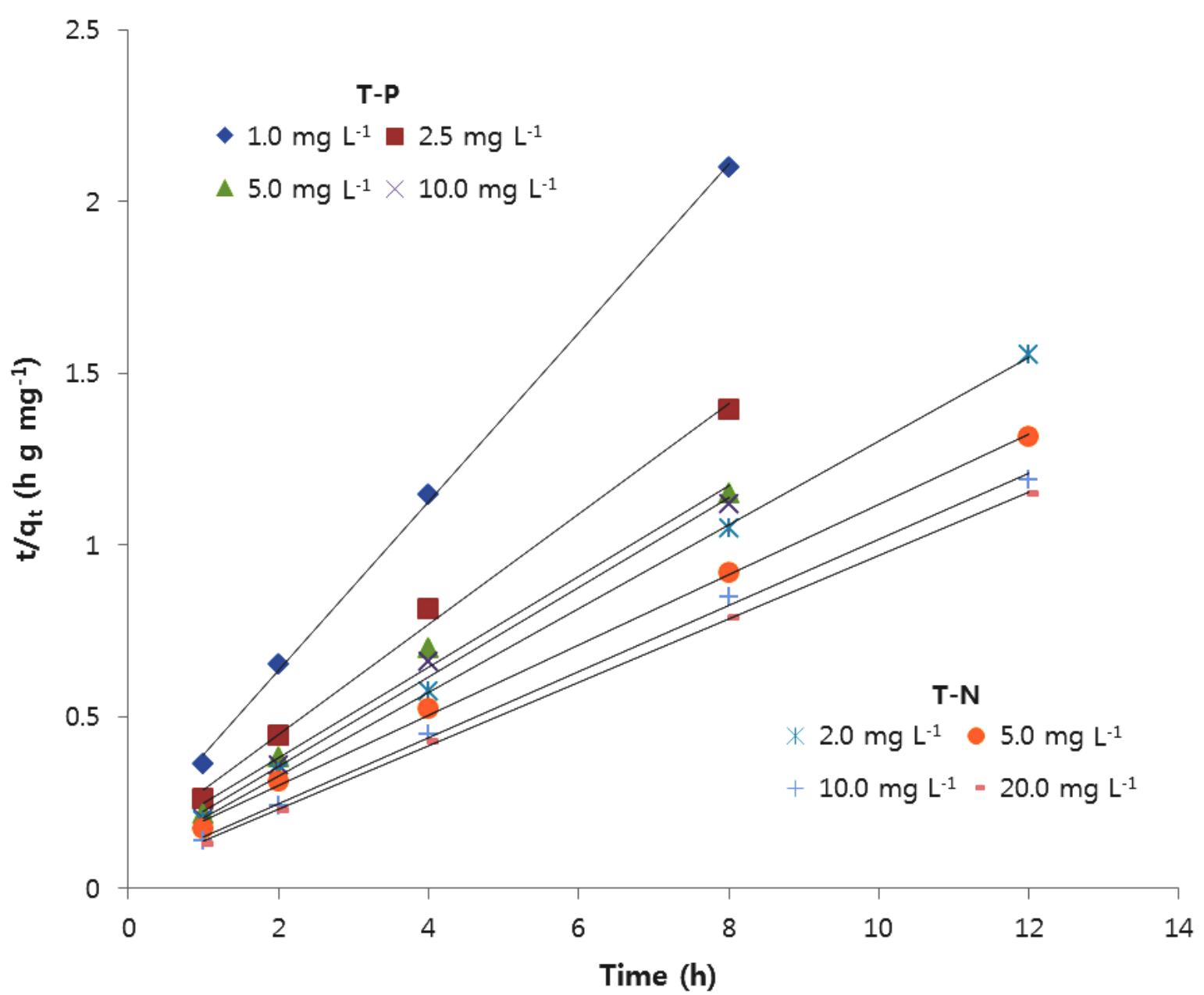

Fig. 5. Plots of pseudo-second-order kinetics of T-N and T-P adsorption on GAC at $298 \mathrm{~K}$. 


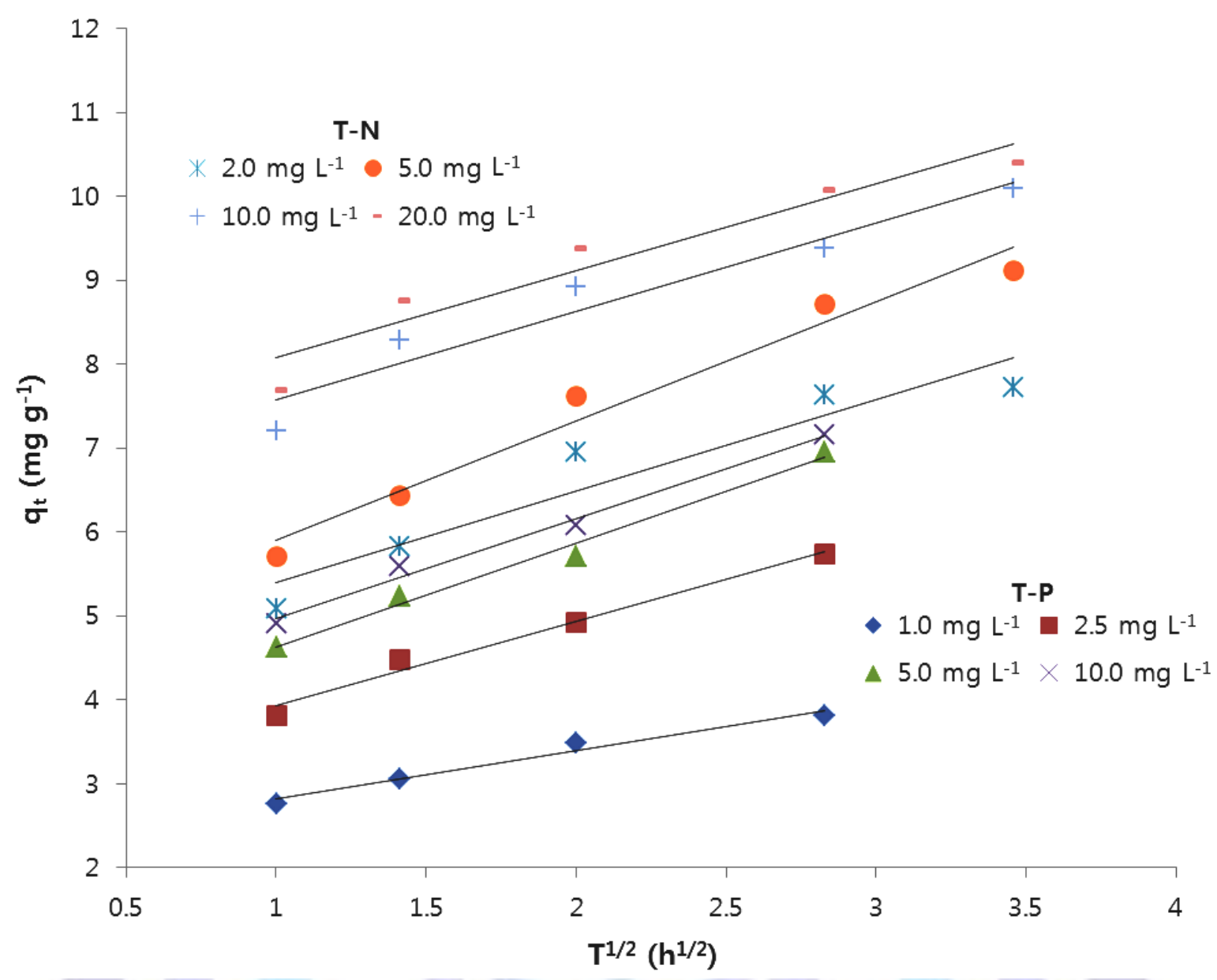

Fig. 6. Plots of intra-particle diffusion kinetics of T-N and T-P adsorption on GAC at $298 \mathrm{~K}$. 


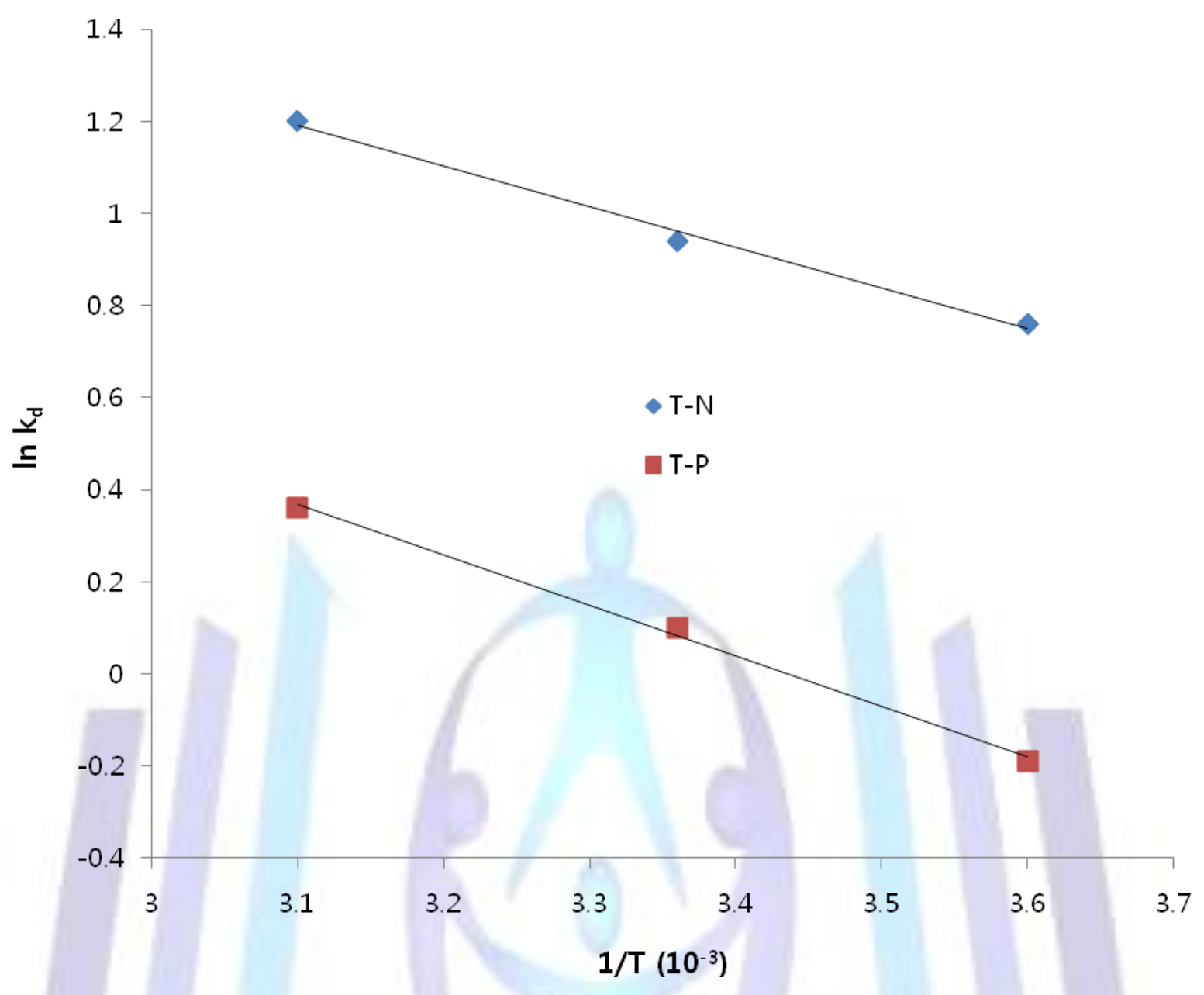

Fig. 7. Plots of In kd versus $1 / \mathrm{T}$. 